\title{
ÔNUS E DEVERES PROCESSUAIS ${ }^{1}$
}

\author{
ONERI E OBBLIGHI PROCESSUALI
}

PROCEDURAL BURDENS AND OBLIGATIONS

\section{RESUMO}

O presente estudo, partindo de revisão bibliográfica, examina as teorias sobre ônus e deveres que trazem contribuições relevantes para a construção dos conceitos, dentre as quais se encontra a formulada por Francesco Carnelutti, cujas ideias foram reproduzidas por vários autores ao longo do século XX.

Palavras-chave: Ônus. Deveres. Direito Processual Civil.

\section{RIASSUNTO}

Il presente studio, sulla base di una rassegna bibliografica, esamina teorie suoneri e dover icheap portano contributi rilevanti alla costruzion equelli concetti, tra cui quella formulata da Francesco Carnelutti, Le cui idee sono state riprodotte da diversi autori nel corso del XX secolo.

Parole chiave: Onere. Obbligo. DirittoProcessuale Civile.

\section{ABSTRACT}

The present study, based on a bibliographyic review, examines the theories about burdensand obligations that bring relevant contributions to the construction of concepts, among which is the one formulated by Francesco Carnelutti, whose ideas were reproduced by several auth or sthrough out the 20th century.

Keywords: Burden. Obligation. Civil Procedure.

\footnotetext{
${ }^{1}$ Este artigo é fruto do trabalho entregue ao fim da disciplina "Bases dogmáticas da ciência processual civil: análise da obra e do pensamento cientifico de Francesco Carnelutti”, ministrada pelo Prof. Tit. José Rogério Cruz e Tucci e pelo Prof. Dr. Heitor Vitor Mendonça Sica, no semestre de 2019.2, na Faculdade de Direito da Universidade de São Paulo.

${ }^{2}$ Doutorando pela Faculdade de Direito da Universidade de São Paulo. Mestre pela Faculdade de Direito do Recife, Universidade Federal de Pernambuco. Professor de Direito Processual Civil. Membro da Associação Norte e Nordeste de Professores de Processo (ANNEP) e do Instituto Brasileiro de Direito Processual (IBDP). Advogado.
} 


\section{INTRODUÇÃO}

As condutas das partes -cumprindo ou ignorando ônus processuais; atendendo ou violando os deveres processuais-fazem com que cada processo encontre um caminho diferente. Apesar da condução pelo magistrado (CPC, art. 139), os processos tomam vida e seguem sua própria sorte, impulsionados pelas condutas das partes. Daí a relevância de compreender tais situações jurídicas (ônus e deveres)

Rigorosamente, tais conceitos são próprios da Teoria Geral do Direito, que são importados para o Direito Processual Civil. As mais diversas teorias do fato jurídico, cuja pretensão é explicar o fenômeno jurídico, trabalham com os conceitos de ônus e de deveres, ou conceitos próximos, no plano da Teoria Geral do Direito. São exemplos, dentre inúmeros: (RÁO, 1961; KELSEN, 1998; ASCENSÃO, 2005; IRTI, 2008; VILANOVA, 2000; CASTRO, 1985; BOBBIO, 2020). ${ }^{3}$

São trabalhos de fôlego que, sob perspectivas e marcos próprios, organizam e arrumam os conceitos da ciência jurídica (DIDIER JR., 2012, p. 37).Porém, não existe uniformidade na construção dos conceitos de ônus e de deveres, o que resulta na indicada dificuldade. Ora, a qualidade de uma teoria decorre de sua capacidade de representar seu objeto e promover a compreensão analítica e pragmática do fenômeno jurídico. Não existe um acerto ou desacerto absoluto de uma teoria, num binômio rigoroso de validade ou invalidade. Cada uma delas contribui em certa medida na construção dos conceitos, com explicações suficientes, adequadas e úteis para explicar o fenômeno jurídico. Quando reunidas e examinadas, de forma coerente, facilitam o trabalho do intérprete e do pesquisador.

O presente trabalhopercorrerá as teorias sobre ônus e deveres que, em seu sentir, trazem contribuições relevantes para a construções dos conceitos, dentre as quais se encontra a formulada por Francesco Carnelutti (1941, 1944, 1997), cujas ideias foram reproduzidas por vários autores ao longo do século XX.

\footnotetext{
${ }^{3}$ Registra-se que muito dessas pesquisas são, na verdade, do campo do Direito Civil, isso porque durante longo tempoapresentava uma metódica que era assimilada e servia de modelo para outras disciplinas do Direito (RODRIGUES JR., 2019).
} 


\section{OS CONCEITOS DE ÔNUS E DE DEVER NO DIREITO PROCESSUAL CIVIL}

\subsection{A RELEVÂNCIA DA DISTINÇÃO PARA O DIREITO PROCESSUAL CIVIL}

As teorias que explicam o processo são diversas. Cada uma delas tem sua relevância histórica e científica, contribuindo para o desenvolvimento do Direito Processual Civil. O que se pode afirmar, com segurança, é que as teorias mais relevantes trabalham com o conceito de ônus e deveres processuais para explicar, de alguma forma, as situações jurídicas processuais.

Seja adotando o conceito de processo como relação jurídica, a exemplo de Bulow (1964), seja fundando-se no conceito de processo como situação jurídica, como faz Goldschmidt (1936 e 2019), seja tomando o processo como um conjunto de atos complexos, na concepção de Carnelutti (1944), seja encarando o processo como procedimento em contraditório, tal qual Fazzalari (1996), seja, ainda, apresentando o processo como acto-procedimento, na lição de Paula Costa e Silva (2019), tais teoriastrabalham com o conceito de ônus e deveres processuais. ${ }^{4}$

Isso, por si só, seria suficiente para demonstrar a relevância da distinção entre ônus e deveres para a ciência processual. Contudo, como afirma Gavazzi (1995, p. 8), os estudos das teorias das situações jurídicas são uma Torre de Babel, merecendo acurada atenção.

Cumpre registrar que os atuais manuais e cursos de Direito Processual Civil, de caráter propedêutico, não se debruçam com profundidade sobre tais conceitos. Com a exceção das Instituições de Direito Processual Civil de Cândido Dinamarco (2017), que dedicam proveitosas páginas ao estudo do tema, os atuais manuais e cursos tratam-lhe secamente ou não $^{5}$ o examinam sequer.

Porém, a despeito disso, ao longo de suas exposições, os atuais manuais e cursos recorrem ao conceito de ônus e deveres para explicar a incidência e a eficácia de inúmeras regras processuais, a exemplo do ônus de impugnação específica dos fatos na contestação, o ônus da prova, os deveres dos sujeitos processuais previstos no art. 77 do CPC etc.

Essa projeção prática também revela a importância da distinção para o Direito Processual Civil. ${ }^{6} \mathrm{Na}$ verdade, o atual $\mathrm{CPC}$ parece conferir relevância às situações jurídicas das

\footnotetext{
${ }^{4}$ Eduardo Coutureapresenta excelentes lições acerca das variadas concepções de processo (COUTURE, 1993).

${ }^{5}$ É o caso de Eduardo Talamini e Luiz Rodrigues Wambier (2018).

${ }^{6}$ É a lição de Helena Abdo (2010, p. 350): “A esta altura, pode-se indagar qual seria a relevância prática do estudo das situações subjetivas processuais, estudo esse que, como alertado no início, é razoavelmente árido e penoso. Ao contrário do que possa parecer à primeira vista, há diversas aplicações práticas da teoria, muitas delas ainda aguardando para serem descobertas. (...) Uma das primeiras projeções práticas de relevância advém, justamente, da diferenciação que se pode estabelecer entre o ônus e o dever".
} 
partes como categorias sensíveis à formação e ao desenvolvimento do processo, aí inclusos os ônus e os deveres processuais, incorporando na redação do arts. $7^{\circ}$ e 190 :

\footnotetext{
“Art. $7^{\circ}$ É assegurada às partes paridade de tratamento em relação ao exercício de direitos e faculdades processuais, aos meios de defesa, aos ônus, aos deveres e à aplicação de sanções processuais, competindo ao juiz zelar pelo efetivo contraditório. Art. 190. Versando o processo sobre direitos que admitam autocomposição, é lícito às partes plenamente capazes estipular mudanças no procedimento para ajustá-lo às especificidades da causa e convencionar sobre os seus ônus, poderes, faculdades e deveres processuais, antes ou durante o processo."
}

Enfim, tudo isso demonstra que o estudo dos conceitos de ônus e deveres tem relevância dogmática para o Direito Processual Civil.

\subsection{AS SITUAÇÕES JURÍDICAS PROCESSUAIS}

Os ônus e deveres processuais são categorias de situações jurídicas processuais. E, a seu turno, as situações jurídicas consistem em eficácias das normas jurídicas. Logo, os ônus e deveres são eficácias de normas jurídicas, ao lado de várias outras.

Tais afirmaçõespressupõem premissas mais claras.

O mundo é um conjunto de fatosou, mais precisamente, um conjunto de eventos (fatos da natureza) e de condutas (fatos humanos) localizados no tempo e espaço (VILANOVA, 2000, p. 137).Um fato é relevante para o Direito, ou seja, o "fato é jurídico na medida em que uma norma a ele vincule efeitos" (VILANOVA, 2000, p. 139). A norma, em seu texto, estabelece sua hipótese de incidência. Quando ocorre no mundo o fato concreto (suporte fático) descrito na hipótese de incidência, há exatamente a incidência da norma sobre o fato concreto, que se torna fato jurídico (MELLO, 2011, p. 18-31; CASTRO, 1985, p. 23-41).

Após a incidência da norma sobre o fato - que se tornou jurídico - passa a irradiar efeitos. "Só de fatos jurídicos provém eficácia jurídica" (PONTES, 1954, p. 4). E os fatos jurídicos podem irradiar uma série de efeitos distintos: são as categorias eficaciais, consistentes em toda sorte de espécies de efeitos jurídicos encontrados no mundo do direito. ${ }^{7}$

\footnotetext{
7“'Denominam-se categorias eficaciais todas as espécies de efeitos jurídicos encontráveis no mundo do direito; desde as mais elementares situações jurídicas às mais complexas relações jurídicas, às sanções, às premiações e aos ônus, todos são categorias de eficácia jurídica" (MELLO, 2011, p. 43).
} 
Tais efeitos jurídicos, numa concepção mais larga (útil ao presente trabalho), correspondem às situações jurídicas (MELLO, 2011, p. 95).

Desse modo, as situações jurídicas designam "toda e qualquer consequência que se produz no mundo jurídico em decorrência de fato jurídico” (MELLO, 2011, p. 95), desde os efeitos mínimos e mais simples até aqueles mais complexos. As situações jurídicas consistem, portanto, nas posições em que o sujeito de direito se encontra no mundo jurídico (MELLO, 2011, p. 95).

Desse modo, encontram-se entre as situações jurídicas, em sentido lato, os direitos, deveres, faculdades, ônus, pretensões, capacidades, competências, legitimidades, exceções, poderes, sujeições etc. São todas posições do sujeito de direito.

Todo esse raciocínio, apresentado em obras de Teoria Geral do Direito, em nada se altera quando se trata especificamente de normas processuais. $^{8}$ Estas incidem sobre os fatos, tornando-os fatos jurídicos processuais. ${ }^{9}$ Por sua vez, os fatos processuais irradiam efeitos que correspondem às situações jurídicas processuais dos sujeitos. E, assim, tais situações jurídicas processuais apresentam-se de formas variadas: deveres processuais, faculdades processuais, ônus processuais, pretensões processuais, capacidades processuais, competências processuais, legitimidades processuais, exceções processuais, poderes processuais, sujeições processuais etc. São as posições em que o sujeito se encontra no processo.

Daí a razão pela qual se afirmou que ônus e deveres processuais são espécies de situações jurídicas processuais, ao lado de várias outras.

\section{O DESENVOLVIMENTO DOS CONCEITOS DE ÔNUS E DE DEVER}

\subsection{A CONTRIBUIÇÃO DE BRUNETTI ${ }^{10}$}

A moderna distinção entre ônus e dever é fruto da evolução da ciência dogmática ao longo de algumas décadas. No pensamento científico moderno, o ponto de partida da distinção

\footnotetext{
${ }^{8}$ Sobre o tema, consultar: Didier Jr. e Nogueira, 2011.

9 “'Como já visto, as situações jurídicas são efeitos de fatos jurídicos, que funcionamcomo sua causa. Tratando as situações jurídicas no plano do Direito Processual,em especial no âmbito da Teoria Geral do Processo já que fato jurídico e situação jurídica são conceitos lógico-jurídicos -, é possível afi rmar que as situações jurídicasprocessuais decorrem de fatos jurídicos processuais" (NOGUEIRA, 2010, p. 757-758).

${ }^{10}$ Duas excelentes pesquisas que se debruçaram sobre o conceito de "regra final" deGiovanni Brunetti: Irti, 2008, p. 107-164; Ramos, 2018, p. 57-61.
} 
foi concebido por Giovanni Brunetti, em sua obra "Norme e Regole Finali nel Diritto", datada de $1913 .^{11}$

Brunettiafasta a ideia de que toda norma é imperativa, ou seja, de que toda norma jurídica tolhe a liberdade de agir do sujeito (BOBBIO, 2010, p. 125). Para tanto, o autor constrói o conceito de "regra final", que exprime, em suas palavras, apenas necessidades finais (ou teleológicas). As regras finais não exprimem necessidades absolutas (BRUNETTI, 1913, p. 61).

Ele apresenta, como exemplo, o seguinte esquema: se queres chegar cedo, deves caminhar rapidamente. Com isso, o autor explica que o "caminhar rapidamente" não é condição necessária por si só para chegar ao ponto de destino, mas apenas consiste em condição necessária com a finalidade de "chegar cedo" ao ponto de destino (BRUNETTI, 1913, p. 61-62). E tal conduta está subordinada à vontade do agente de querer chegar cedo. A finalidade (chegar cedo) depende da vontade do agente que poderá, ou não, adotar a conduta (caminhar rapidamente).

Em suas palavras, ora traduzidas: "'é necessário que tu caminhes rapidamente" representa uma necessidade, que não é absoluta, mas final, um dever, que não é absoluto, mas que podemos chamar final, porque é subordinado ao fim, que depende da vontade do agente"(BRUNETTI, 1913, p. 62).

Resumidamente, Brunettierigiu a seguinte classificação: de um lado, as regras finais, que se fundam nos deveres livres ou finais; doutro lado, as regras imperativas, que se fundam nos deveres absolutos (BRUNETTI, 1913, p. 73).

A regra imperativa traz um comando, traduzido num dever absoluto. $O$ esquema é simples: deves agir no modo $\mathrm{A}$. Se o agente não quer agir no modo $\mathrm{A}$, é irrelevante, pois há um comando que deve ser obedecido. Se o agente deixa de agir no modo A, há violação da regra imperativa. Há, portanto, desobediência (BRUNETTI, 1913, p. 75).

Já a regra final traz uma finalidade, exprimindo um dever final ou também chamado de dever livre. O esquema apresentado é diferente: se queres $B$, deves agir no modo $A$. Não há nesse esquema um comando ou imperatividade. $\mathrm{O}$ agir fica subordinado à vontade do agente de obter o fim previsto na norma. Se o agente deixar de adotar a conduta, não há violação à regra. Existiria, portanto, liberdade de conduta. O agente é livre para adotar a conduta, daí por que se denominou "dever livre". As regras finais seriam facultativas, não obrigatórias (BRUNETTI, 1913 , p. 73-74).

\footnotetext{
11 “Atribui-se a Brunettia primeira teorização a respeito do ônus” (GRAU, 1982, p. 179). No mesmo sentido, atribuindo aBrunetti a primeira ideia do conceito de ônus: Scozzafava, 1980, p. 100-101. Em sentido contrário: Aubert, 2019, p. 15.
} 
Aplicando a teoria de BRUNETTI ao atual procedimento executório, conclui-se que o art. 520 do CPC, ao prever o cumprimento provisório de sentença, estabelece uma regra final. A promoção do cumprimento provisório é um dever livre, que o exequente pode ou não adotar. O esquema pode ser assim resumido: se quiseres acelerar os atos executivos na pendência de recurso sem efeito suspensivo, poderás promover o cumprimento provisório. O exequente não é obrigado a executar provisoriamente, há margem de escolha subordinada à sua vontade de acelerar os atos executivos.

As ideias de Brunetti, enfim, consistem no início da teorização da categoria que atualmente é conhecida por ônus (RAMOS, 2018, p. 59). É quando a noção de ônus jurídico passa a ganhar contornos próprios, desgarrando, descolando, desprendendo do conceito de dever jurídico.

Vitor de Paula Ramos aponta três relevantes contribuições do trabalho de Brunetti. A primeira delas, seria a percepção de que há regras (as chamadas regras finais) cujo descumprimento dos comportamentos por elas estabelecidos não implica violação à regra. Em outras palavras, deixar de adotar comportamento da regra não provoca um ilícito. Não há ato contrário ao Direito (RAMOS, 2018, p. 60).

A segunda contribuição foi perceber que as regras finais deixam margem de escolha para o destinatário da regra. O agente é livre para adotar o comportamento A, sabendo que se deixar de adotá-lo não alcançará o fím B, porém não incorrerá em ilícito (RAMOS, 2018, p. 60).

A terceira contribuição consistiu em demonstrar que o fato de o Direito tratar uma conduta como dever absoluto ou dever livre consiste em tema que deve ser encarado pela fonte produtora da norma, a exemplo do Poder Legislativo (RAMOS, 2018, p. 60-61). Assim, se uma conduta será obrigatória ou facultativa, se seu descumprimento implicará um ilícito ou apenas uma situação de desvantagem, é questão que o Poder Legislativo deve enfrentar, ao editar o texto legal. O ordenamento jurídico, para promover seus fins, poderá conferir mais ou menos liberdade aos destinatários - impondo-lhe deveres ou ônus - e isso, em suma, é questão a ser enfrentada pela fonte produtora de normas.

Claro que a teoria de Brunetti não é infensa a críticas. A primeira delas é de Natalino Irti, ao criticar o caráter psicológico do esquema da regra final. Ao construir o esquema "se queres $B$, deves agir $A$ ”, Brunetti conferia valor à vontade humana impossível de se aferir juridicamente, já que mensurada no plano subjetivo e individual do agente (IRTI, 2008, p. 113116). A conduta do agente decorreria de um "cálculo eventual e interior, com o qual o particular determina a própria vontade e adota os instrumentos jurídicosmais úteis e oportunos" (IRTI, 
2008, p. 117). A vontade nasceria e morreria dentro do agente, sendo irrelevantejuridicamente para definir se a regra estabeleceu um dever absoluto ou livre (IRTI, 2008, p. 117-119).

A segunda crítica, empreendida por BOBBIO, seria a contradição da expressão dever livre: "na verdade o que é livre, nas regras finais, é o fim, mas o fim, justamente por ser livre, não é obrigatório; o que é obrigatório é o meio, mas justamente pelo fato de ser obrigatório, uma vez escolhido o fim, deixa de ser livre." (BOBBIO, 2010, p. 127). Desse modo, qualificar o dever como livre seria negar o próprio dever (IRTI, 2008, p. 117-119).

Apesar das críticas, a teoria de Brunetti se revelou como original, contribuindo efetivamente para a construção, ao menos na modernidade, do conceito de ônus.

\subsubsection{A Contribuição de Carnelutti}

Após a construção de Brunetti, destaca-se a teoria de Francesco Carnelutti, cuja obra jurídica $^{12}$ - com aspirações de completude - se debruçou sobre as situações jurídicas. Basicamente, três obras expõem a ideia de Carnelutti sobre ônus e deveres: Sistema Del Diritto Processuale Civile (1936), Teoria Generale del Diritto (1940) e Instituzionidel Nuovo processo Civile Italiano (1941).

Mais precisamente, Carneluttiparte da diferença entre interesse próprio e interesse alheio para distinguir ônus e deveres. Ônus e deveres possuem, em comum, um elemento formal, que seria a vinculação da vontade do agente; contudo, o dever vincula a vontade do agente em proteger interesse alheio, ao passo que o ônus vincula a vontade do agente em proteger interesse próprio (CARNELUTTI, 1944, p. 65; 1941, p. 190).

As normas jurídicas destinam-se a tutelar interesses de sujeitos, atuando sobre as suas vontades, de modo a imporou estimular as suas condutas. Especificamente no processo, por exemplo, os atos realizados (que formam o processo) consistem sempre no sacrifício do interesse de um sujeito (CARNELUTTI, 1944, p. 621). Para que o processo prossiga e obtenha a composição do litígio, é preciso que sejam impostas condutas às partes, atuando sobre as suas vontades. Assim, quando uma parte adota uma conduta está sempre sacrificando o seu interesse, pois sempre gasta tempo que poderia utilizar em outras condutas que lhes fosse útil (CARNELUTTI, 1944, p. 621-622).

\footnotetext{
${ }^{12}$ Para um exame da contribuição de Carnelutti para o Direito Processual Civil: Tucci, 2017. Já para um exame completo da bibliografia deCarnelutti, em todas as áreas da ciência jurídica: Tarello, 1974, p. 499-598.
} 
Contudo, esse interesse sacrificado pode ter duas finalidades: ou proteger interesse do próprio destinatário da norma ou, por outro lado, proteger interesse alheio, daquele que não é o destinatário da norma.

No caso do processo, se o interesse de algum sujeito surge como obstáculo para a composição do litígio, impedindo a satisfação do interesse de outro sujeito, a norma estabelece um dever, para que um interesse prevaleça sobre outro. Em outras palavras, o dever estabelece uma conduta que será obrigatória para o agente (sem margem de escolha) para proteger direito alheio, de modo que se obtenha a composição do litígio (CARNELUTTI, 1944, p. 621-623). Em virtude do dever, o sujeito sacrifica o interesse próprio - obrigatoriamente - em benefício do interesse alheio.

Aplicando a teoria ao direito vigente, o art. 774, II, do CPC estabelece que se considera atentatória à dignidade da justiça a conduta comissiva ou omissiva do executado que dificulta ou embaraça a realização da penhora. É um típico caso de dever na teoria de Carnelutti. A satisfação do crédito executadoé o objetivo do processo executório, em benefício do interesse do exequente. Desse modo, a penhora deve ocorrer para que o interesse do exequente seja atendido. $\mathrm{O}$ art. 774, II, do CPC impõe um dever para o executado, na medida em que este sacrifica seu interesse (de não ter seus bens penhorados) em favor do interesse do exequente (de obter a penhora dos bens para posterior satisfação do crédito).

Assim, o dever consiste na subordinação de interesse do sujeito a um interesse alheio. Douto lado, o ônus consiste na subordinação do interesse do sujeito a interesse próprio (CARNELUTTI, 1941, p. 190).

Melhor explicando o ônus. Por vezes, há condutas que são necessárias ou úteis ao processo, fazendo com que interesses sejam atendidos, contudo o destinatário da conduta que é exatamente aquele cujo interesse é protegido. Nessas hipóteses, não se protege interesse alheio, mas se protege, na verdade, interesse próprio. Quando há um ônus, o agente sacrifica um interesse próprio em benefício de outro interesse também próprio, daí por que ele tem margem de escolha para agir ou não. Inexiste obrigatoriedade de conduta, é uma opção do sujeito agir ou não, sabendo que se agir, poderá obter uma situação de vantagem (CARNELUTTI, 1944, p. 65; 1941, p. 190; 1997, p. 331-332). A liberdade decorre, exatamente, da intersubjetividade do conflito de interesses, que dizem respeito ao mesmo sujeito; é uma opção dele agir ou não, sabendo que poderá alcançar uma posição processual melhor.

Em exemplos atuais, o protesto de decisão judicial, nos termos do art. 517 do CPC, configura um ônus processual. Isso porque o exequente tem a liberdade de efetuar ou não o 
protesto. O conflito de interesses é interno: o exequente poderá sacrificar interesses próprios (gastar tempo e dinheiro com a realização do protesto) para obter uma vantagem na execução, em favor de interesse próprio (efetivar uma medida que provoca a inclusão do executado no cadastro de inadimplentes).

Carnelutti afirma que a violação do dever consiste num ato ilícito, como forma de garantir a proteção do interesse alheio (CARNELUTTI, 1944, p. 62; 1941, p. 231). Por outro lado, o descumprimento de um ônus - exatamente por ser livre - não provocaato ilícito; o ônus encarta a figura do ato necessário para se obter um fim (CARNELUTTI, 1941, p. 190 e 232). Assim, voltando aos exemplos, o executado que embaraça a realização da penhora descumpre um dever e pratica um ato ilícito. Já o exequente que deixa de protestar a decisão judicial deixou apenas de praticar um ato necessário, porém sem qualquer antijuridicidade.

Como se vê, toda a ideia de Carnelutti repousa sobre o conflito de interesses. E o autor confere expressamente um viés econômico a sua perspectiva do ônus processual. Ele afirma que a escolha do sujeito está ligada a umcálculo justo entre seus interesses em jogo. O sujeito, na hipótese dos ônus, irá agir se o litígio merecer gastos no processo (CARNELUTTI, 1944, p. 81). O ônus funcionaria como um "estímulo" ou como "sanção econômica" para induzir a prática do ato: "ou o exercita a parte, ou não poderá obter de outro modo a tutela de seu interesse" (CARNELUTTI, 1944, p. 81). Enfim, o móvel do ônus seria uma questão econômica, avaliada pela parte.

\subsubsection{A Posição de Betti e de Goldschmidt}

As posições de Emilio Betti e de James Goldschmidt compartilham das ideias de Carnelutti, uma vez que encaram o ônus como imperativo do próprio interesse (AUBERT, 2019, p. 18-20).

Betti afirma que o mérito de definir a figura do ônus e diferenciá-la do dever coube aos pesquisadores do Processo Civil (BETTI, 1965, p. 57). Ao confrontar as duas figuras, BETTI segue a linha de Carnelutti, afirmando que o ônus traz uma necessidade de um sujeito agir, porém o prejuízo da omissão em agir é sentido pelo próprio agente (BETTI, 1965, p. 57). O dever seria uma ação imposta em benefício de interesse alheio, enquanto o ônus seria ação em interesse próprio, para se alcançar um vantagem ou evitar um prejuízo. Seria lógico, já que a conduta é estabelecida em favor do próprio agente, que este suporte as consequências de sua 
omissão, de uma conduta incompatível ou, ainda, de seu exercício inadequado (BETTI, 1965, p. 57, 2018, p. 57; LENT, p. 156).

Segundo Irti, a concepção de Betti está fundada na noção de autorresponsabilidade, pois o ônus provoca uma conexão entre risco e a iniciativa conferida ao sujeito de agir ou deixar de agir (IRTI, 2008, p. 134). A autorresponsabilidade, nos ônus, significa que a parte, e apenas ela, suportará às consequências imprevistas e por vezes danosas, de um exercício equivocado ou inadequado da conduta (BETTI, 2008, p. 58).

Trazendo a lição de Betti para atualidade, é possível afirmar que a responsabilidade objetiva do exequente, ao promover o cumprimento provisório de sentença (CPC, art. 520, I), caracteriza uma autorresponsabilidade no exercício do ônus. Foi dito acima, que o cumprimento provisório de sentença consiste num ônus do exequente, pois tem liberdade de promovê-lo caso queria encetar atos executivo mais rápido. Contudo, ao exercer tal ônus, o exequente - e somente ele - assume o risco de reparar os danos causados ao executado, caso sobrevenha reforma da decisão executada.

Goldschmidt (1936, p. 8), que sustenta ser o conceito de relação jurídica obscuro e insuficiente para explicar a natureza jurídica do processo. Isso porque os vínculos jurídicos que surgem das normas processuais não seriam relações jurídicas (caráter estático do Direito), mas seriam situações jurídicas (caráter dinâmico do Direito), traduzidas em expectativas, possibilidades e ônus.

Rechaçando a figura do dever no Direito Processual, ao examinar o direito alemão vigente, ${ }^{13}$ Goldschmidt coloca o ônus como situação jurídica central do processo. O ônus processual seria uma situação de necessidade de praticar determinado ato para evitar que sobreviesse um prejuízo processual. "Conotraspalavras, se trata de imperativos del próprio interés" (GOLDSCHMIDT, 1936, p. 203). Os ônus guardariam relação próxima com as possibilidades processuais, tendo em vista que a possibilidade exige da parte que seja diligente para evitar um prejuízo.

Para Goldschmidt, os ônus são perfeitos ou menos perfeitos. O descumprimento de um ônus perfeitos acarretaria necessariamente um prejuízo. Já o ônus imperfeito pode eventualmente implicar um prejuízo (GOLDSCHMIDT, 1936, p. 203).

Assim, na concepção de Goldschmidt, a substituição da penhora, estabelecida no art.847 do CPC, seria um ônus perfeito. Mais precisamente, o art. 847 dispõe que o executado

\footnotetext{
13 "Fueradeldeber de comparecencia, no existe enelDerecho vigenteninguna outra obligación de las partes ni ningúndeber de abstención.” (GOLDSCHMIDT, 1936, p. 201-202).
} 
poderá requerer a substituição do bem penhorado, desde que comprove a menor onerosidade e, em caso de bens imóveis, comprove as matrículas e as certidões, conforme inciso I do mesmo dispositivo. Desse modo, é um ônus doexecutado - na medida de seu próprio interesse em substituir o bem penhorado - comprovar a propriedade do imóvel ofertado à penhora; caso não haja essa comprovação, não poderá ser obtida a substituição da penhora. É, portanto, um ônus perfeito, já que o prejuízo será inevitável (indeferimento do pedido de substituição da penhora).

Por outro lado, o art. 798, II, c, do CPC prevê um ônus imperfeito. Segundo o dispositivo, ao propor a execução, incumbe ao exequente indicar os bens suscetíveis de penhora do executado. É um ônus, pois a conduta (indicar bens à penhora na petição inicial) é estabelecida em favor do interesse do próprio exequente (garantia da execução e satisfação do crédito), contudo é ônus imperfeito, pois seu descumprimento não provoca necessariamente uma situação de desvantagem para o exequente.

Como dito, as posições de Betti e Goldschmidt, embora muito próximas à de Carnelutti, contribuem com pequenas características que são agregadas ao conceito de ônus e deveres.

\subsubsection{A Contribuição de Gavazzi}

Giacomo Gavazzi (1985) escreveu uma obra específica sobre o conceito de ônus, "L'onere: tra la liberta e l'bbligo".

Em sua obra, o autor faz uma crítica àconcepção individualista e estritamente econômica de interesse, utilizada por Carnelutti para erigir o conceito de ônus. ${ }^{14}$ Tais críticas podem ser reconduzidas a Betti e de Goldschmidt na medida que também adotam a ideia de ônus como imperativo do próprio interesse. Gavazzi afirma que ao considerar um interesse estritamente individual, Carnelutti acaba por afastar da figura do ônus os interesses de natureza pública (1985, p. 55). O autor afirma que o ônus pode ser utilizado tanto para proteger interessespróprios como interesses públicos (que seriam alheios). ${ }^{15}$

Um exemplo atual ajuda a ilustrar a crítica de Gavazzi. No Brasil, por força do art. $14, \S 1^{0}$, I, da Constituição, o voto em eleições políticas é obrigatório, constituindo, portanto, um

\footnotetext{
14 “La teoria carneluttiana presenta l'onere in una prospettivasquisitamenteindividualistica; si direbbeche l'onere sia ilregnodellalibertàindividuale” (GAVAZZI, 1985, p. 53).

${ }^{15}$ MICHELE TARUFFO explica que a ideia de Gavazzi também se observa no contexto do processo, na medida que - sob uma tônica publicística - não se destina apenas a solução de conflitos privados, mas também a atender o interesse público de apresentar decisões justas fundadas em aplicação correta das normas no caso concreto (Em: TARUFFO, 2013, p. 424-425)
} 
dever. Na concepção de Carnelutti, seria um imperativo de interesse alheio (no caso, o interesse público de garantir as eleições políticas). Contudo, o inciso II do mesmo dispositivo afirma que o voto é facultativo para os analfabetos. Nessa hipótese de voto facultativo, a teoria de Carnelutti não conseguiria explicar a regra. Não corresponderia a um dever, pois haveria a faculdade de votar, inexistindo ilícito na omissão. Por outro lado, também não consistiria num ônus porque o imperativo seria em interesse alheio (de natureza pública). Gavazzi, na verdade, diz que não seriam características excludentes, sendo possível existir um ônus em interesse alheio, quando tal interesse for de natureza pública.

$\mathrm{Na}$ verdade, a crítica de Gavazzi pode ser intensificada, tal qual fez IRTI, ao afirmar que é muito difícil aferir, em várias situações, se o sujeito agiu em interesse próprio ou interesse alheio $(2008,136)$.O cálculo econômico que faz o sujeito, antes de agir ou se omitir, é realizado internamente, sendo de difícil valoração jurídica (IRTI, 2008, p. 135-138). No fim das contas, não é fácil identificar se o móvel da conduta do sujeito foi o interesse próprio ou o interesse alheio (RAMOS, 2018, p. 66); até mesmo as normas que estabelecem ônus deixam margem para essa dúvida.

Por exemplo, o art. 520, IV, do CPC, estabelece que, no cumprimento provisório de sentença, o levantamento de depósito em dinheiro fica condicionado à caução idônea e suficiente. Nesse caso, o exequente adota a conduta (apresentar caução) para satisfazer um interesse próprio(receber o dinheiro) ou, por outro lado, para progeter um interesse alheio (do credor, de ter a execução provisória devidamente garantida, já que pende recurso de julgamento)? É uma pergunta de difícil resposta. Talvez a regra exerça as duas funções: garantir interesse próprio do exequente e, também, proteger interesse alheio do executado.

Fica claro, portanto, que a distinção entre imperativo do próprio interesse e de interesse alheio não é um bom critério para distinguir ônus e deveres processuais.

Registra-se, ainda, que Carnelutti confere ao ônus uma perspectiva ecômica, que não haveria no dever. Em relação ao dever, o sujeito agiria em virtude da obrigatoriedade da conduta; enquanto no ônus o sujeito adotaria a conduta após realizar um cálculo econômico, ponderando os gastos, os riscos e as possíveis vantagens da conduta (1944, p. 41).

Com o desenvolvimento da Análise Econômica do Direito, inclusive com pesquisas no campo do Direito Processul Civil (ABREU, 2018; WOLKART, 2019), é possível afirmar que o racional econômico está em todos os atos do processo, incluindo os deveres e os ônus. Ora, os atos do processo são condutas humanas e "o cálculo econômico é atividade indissociável da ação humana”(ABREU, 2018, p. 110). Desse modo, também no dever, apesar de sua obrigatoriedade, 
há um cálculo econômico do agente, que envolve, além dos custos de suaação,os riscos do descumprimento.

Pondo em exemplo, o art. 774, V, do CPC, impõe o dever para o executado de indicar bens à penhora e, em caso de descumprimento, este poderá sofrer multa de até $20 \%$ (vinte por cento) do valor do débito. Há claramente um dever. Mas nada impede que o executado faça o cálculo - econômico - do risco de sofrer a multa com risco de perder um valioso bem imóvel, que seria suficiente para satisfazer a execução. Dessa forma, o executado acabar por descumprir um dever processual, em benefício de interesse próprio, arriscando sujeitar-se à sanção processual.

Isso também demonstra que o critério de imperativo de interesse, construído por Carnelutti, não consegue fornecer boas respostas para diferenciar os ônus e os deveres processuais.

\subsubsection{O Conceito de Ônus e de Dever Processuais}

As ideias de Carnelutti, Betti e Goldschmidt foram incorporadas pela doutrina brasileira. ${ }^{16}$ Duas características, consideradas como essenciais, para diferenciar ônus e deveres são reproduzidas ao longo das décadas, sempre que se buscou explicar algum ônus processual. $\mathrm{Na}$ verdade, não apenas na doutrina brasileira, mas também em países de língua italiana, portuguesa e espanhola.

A primeira característica, como visto, seriade que o ônus veicula um imperativo de interesse próprio para obter uma vantagem ou evitar uma desvantagem. Já o dever seria imperativo de interessealheio, para evitar um prejuízo de terceiro. ${ }^{17}$

Já a segunda característica, seria de que o dever impõe ao sujeito uma conduta obrigatória, sem margem de escolha, de modo que o seu descumprimento configura um ato

\footnotetext{
16 "Nesse quadro científico é que o ônus ganha relevância teórica e assume a posição de relevo em que o encontramos na teoria processual contemporânea, aí incluída a processualística brasileira cuja filiação às formulaçõescarneluttianas não poderia ser exage-rada.55 Aliás, no caso da previsão do art. 341 do CPC/2015, reformulação do art. 302 do CPC/1973, tal filiação é evidenciada pela importância que Buzaid. conferiu à teorização deCarnelutti sobre a noção de ônus e, mais genericamente, sobre as posições jurídicas, em texto publicado no mesmo ano que seu anteprojeto do futuro CPC/1973 (cf. item 9.2, infra). Tampouco é desprezivel a influência exercida por Goldschmidt” (AUBERT, 2019, p. 22).

17 "O vínculo é impôsto, quando há obrigação, para a tutela de interêsse alheio, enquanto, havendo ônus, a tutela é de um interêsse próprio"(BUZAID, 1961, p. 14); "La carga es un imperativo delpropriointerés" (COUTURE, 1993, p. 212); "Ônus é, por definição, um imperativo do próprio interesse”(DINAMARCO, 2017, p. 235); "O ônus é um imperativo em função do próprio interesse daquele a quem é imposto" (MARQUES, 1992, p. 261). No mesmo sentido:Macêdo e Peixoto, 2016, p. 81-82;Talamini e Wambier, 2018, p. 50-53;Sica, 2008, p. 99-103;Grau, 1982, p. 177-183;pontes de Miranda, 1979, p. 322; Stefano, 1980, p. 114; Dinamarco, 2007, p. 41-49; Didier JR. e Nogueira, 2011, p. 126.
} 
ilícito reprimível por uma sanção. Doutro lado, o ônus estabelece uma conduta facultativa, que confere ao sujeito margem de escolha de agir ou se omitir, não incorrendo em ilicitude caso prefira não adotar a conduta; não haveria sanção pelo descumprimento do ônus. ${ }^{18}$

Como se viu, o critério do imperativo do próprio interesse ou do interesse alheio se revela falha e insuficiente, já que em inúmeras ocasiões não é possível aferir se a conduta é imposta em interesse do agente ou não. Desse modo, o presente trabalho afasta tal critério.

As notas distintivas - úteis na pragmática - entre ônus e deveres seriam, portanto, a liberdade de agir, sem incorrer em sanção, garantindo-lhe uma possibilidade de alcançar um efeito jurídico futuro.

Dissecando a afirmação. O dever estabelece uma conduta obrigatória, de modo que não há opção para o sujeito. Este é obrigado a adotar a conduta. Caso não seja adotada, há ato ilícito, contrário ao Direito, incorrendo em sanção. O descumprimento de um dever provoca uma sanção.

Já o ônus caracteriza-se por uma conduta facultativa do sujeito. Este é livre para agir ou se omitir. Sendo de sua livre escolha, a omissão não consiste em ato ilícito, inexistindo qualquer sanção. Ao agir, surge a possibilidade de, eventualmente, ocorrer efeitos jurídicos os mais variados possíveis, que podem ser vantagens para o sujeito ou, ainda, obstar uma situação de desvantagem.

Observando, portanto, tais conceitos na interpretação das regras sobre execução, é possível encontrar alguns exemplos.

$\mathrm{O}$ art. $523, \S 1^{\circ}$, do $\mathrm{CPC}$, ao conceder prazo de 15 (quinze) dias para o executado pagar voluntariamente a obrigação, sob pena de multa de $10 \%$ (dez por cento) é claramente um dever processual na execução. A conduta imposta ao executado é obrigatória, ou seja, não há margem de escolha, restando-lhe apenas praticar o ato. Caso não efetue o pagamento, incorre em ato ilícito processual, de modo que sofre uma sanção, a multa. A conduta, portanto, evita a aplicação de uma sanção.

Doutro lado, o art. 525, $\S 1^{\circ}$, do CPC, ao dispor sobre a impugnação ao cumprimento de sentença encarta um ônus processual. Isso porque é uma faculdade do executado apresentar sua impugnação. Não existe obrigatoriedade na apresentação de defesa. Caso o executado não

\footnotetext{
${ }^{18}$ Buzaid, 1961, p. 14-16; Didier JR. e Nogueira, 2011, p. 128; Silva, 2019, p. 131-133; Couture, 1993, p. 211-213;Dinamarco, 2017, p. 235-237; Marques, 1992, p.261-271;Macêdo e Peixoto, 2016, p. 81-82; SICA, 2008, p. 99-103; CARPES, 2017, p. 32; GRAU, 1982, p. 177-183;LENT, 1954, p. 157-158; Varela, 2000, p. 57-59; Dinamarco, 2007, p. 41-49.
} 
impugne a execução, não haverá qualquer ato ilícito tampouco aplicação de sanção processual. Contudo, caso haja a impugnação, é possível que obtenha um efeito jurídico vantajoso, a exemplo de extinção do cumprimento, redução do valor cobrado, exclusão do polo passivo etc. Mas é importante observar que o efeito jurídico vantajoso não decorre automaticamente do ato de impugnar; é apenas uma possibilidade que dependerá de outras circunstâncias processuais.

\section{SÍNTESE DO ARTIGO}

O presente artigo, após percorrer a construção moderna do conceito de ônus e deveres processuais, que tem como principal expoente, ao menos na doutrina brasileira, a obra de Francesco Carnelutti, conclui que uma das principais características usualmente utilizadaspara identificar se a regra estabelece um dever ou um ônus seria insuficiente: o imperativo do interesse próprio ou do interesse alheio.

Desse modo, as notas distintivas que, pragmaticamente, contribuem para a interpretação da norma e identificação se dispõe um dever ou ônus repousam basicamente na liberdade de conduta. O dever processual é conduta obrigatoria, cujo descumprimento é ato ilícito que importa numa sanção processual. Já o ônus é conduta facultativa, que se não for adotadaas consequências não são ilícitas, mas apenas consequências jurídicas não serão alcançadas.

\section{REFERÊNCIAS}

ABDO, Helena. As Situações Jurídicas Processuais e o Processo Civil Contemporânea. In: DIDIER JR., Fredie (org.) Teoria do Processo: panorama doutrinário mundial. Salvador: Juspodivm, 2010.

ABREU, Rafael Sirangelo Belmonte de. O Processo Civil entre o Jurídico e o Econômico: o caráter institucional e estratégico do fenômeno processual. Tese (Doutorado) - UFRGS, Porto Alegre, 2018.

ASCENSÃO, José de Oliveira. O Direito. 13.ed. Coimbra: Almedina, 2005.

AUBERT, Eduardo Henrik. A impugnação especificada dos fatos no processo civil brasileiro. Tese (Doutorado) - USP, São Paulo, 2019.

BETTI, Emilio. Dirittoprocessualecivile italiano. Nápoles: Edizioni Scientifiche Italiane, 2018.

BETTI, Emilio. Enciclopedia del Diritto. Dovere. Milão: Giuffrè, 1965. p. 53-58. 
BOBBIO, Norberto. Teoria Geral do Direito. Trad. Denise Agostinetti. 3. ed. São Paulo: Martins Fontes, 2010.

BRUNETTI, Giovanni. Norme e RegoliFinali nel Diritto. Torino: UTET, 1913.

BÜLOW, Oskar Von. La Teoria de Las Excepciones Procesales y Presupuestos Procesales. Trad. Miguel Angel Rosas Lichtstein. Buenos Aires: EJEA, 1964.

BUZAID, Alfredo. Do ônus da prova. Revista de Direito Processual Civil, São Paulo, v. 4, p. 5 24, jul./dez.1961.

CARNELUTTI, Francesco. Instituciones del Proceso Civil. Trad. Santiago Sentís Melendo. Buenos Aires: El foro, 1997. v. 1.

CARNELUTTI, Francesco. Sistema de derecho Procesal civil. Trad. Niceto Alcalá-Zamora y Castillo e Santiago Sentís Melendo. Buenos Aires: UTEHA, 1944. v. 1.

CARNELUTTI, Francesco. Sistema de derecho Procesal civil. Trad. Niceto Alcalá-Zamora y Castillo e Santiago Sentís Melendo. Buenos Aires: UTEHA, 1944, v. 2.

CARNELUTTI, Francesco. Teoría General del Derecho. Trad. Carlos G. Posada. Madri: ERDP, 1941.p. 190.

CARPES, Artur Thompsen. Onus da prova no Novo CPC: do estático ao dinâmico. São Paulo: RT, 2017.

CASTRO, Torquato. Teoria da Situação Jurídica em Direito Privado Nacional. São Paulo: Saraiva, 1985.

COUTURE, Eduardo J. Fundamentos del Derecho Procesal Civil. 3.ed. Buenos Aires: Depalma, 1993.

DIDIER JR., Fredie. Sobre a teoria geral do processo, essa desconhecida. Salvador: Juspodivm, 2012.

DIDIER JR., Fredie; NOGUEIRA, Pedro Henrique Pedrosa. Teoria dos fatos jurídicos processuais. Salvador: Juspodivm, 2011.

DINAMARCO, Cândido Rangel. Instituições de Direito Processual Civil. 7.ed. São Paulo: Malheiros, 2017.v. 2.

DINAMARCO, Pedro da Silva. Onus processuais: limites à aplicação das consequências previstas para o seu não-cumprimento. Tese (Doutorado) - USP, São Paulo, 2007.

FAZZALARI, Elio. Instituzioni di Diritto Processuale. 8.ed. Milão: CEDAM, 1996.

GAVAZZI, Giacomo. L'onere: Tralalibertà e l'obbligo. Torino: Giappichelli, 1985.

GOLDSCHMIDT, James.Derecho Procesal Civil. Trad. Leonardo Prieto Castro. Barcelona: Labor, 1936. 
GRAU, Eros Roberto. Nota sobre a distinção entre obrigação, dever e ônus. Revista da Faculdade de Direito da USP, São Paulo, v. 77, p. 177-183, jan./dez., 1982.

GRECO, Leonardo. O processo de execução. Rio de Janeiro: Renovar, 1999.p. 158.v. 1.

GUERRA, Marcelo Lima. Direitos fundamentais e a proteção do credor na execução civil. São Paulo: RT, 2003.

IRTI, Natalino. La perfezione de gliattigiuridici e ilconcettodi onere. Saggidi Teoria Generale del Diritto. Milão: Giuffrè, 2008.

KELSEN, Hans. Teoria Pura do Direito. Trad. João Baptisa Machado. 6. ed. São Paulo: Martins Fontes, 1998.

LENT, Friedrich. Obblighi e onerinel processo civile. Rivista di Diritto Processuale, Padova, v. 9, p. 150-158, 1954.

MACÊDO, Lucas Buril de; PEIXOTO, Ravi Medeiros. Ônus da prova e sua dinamização. 2. ed. Salvador: Juspodivm, 2016.

MARQUES, José Frederico. Instituições de Direito Processual Civil. Campinas: Millennium, 1992. v. 2.

MELLO, Marcos Bernardes de. Teoria do Fato Jurídico: plano da eficácia. 7. ed. São Paulo: Saraiva, 2011.

NOGUEIRA, Pedro Henrique Pedrosa. Situações Jurídicas Processuais. In: DIDIER JR., Fredie (org.).Teoria do Processo: panorama doutrinário mundial. Salvador: Juspodivm, 2010.

PONTES DE MIRANDA, Francisco Cavalcanti. Comentários ao Código de Processo Civil. 2. ed. Rio de Janeiro: Forense, 1979. t. 4.

PONTES DE MIRANDA, Francisco Cavalcanti. Tratado de Direito Privado. Rio de Janeiro: Borsoi, 1954. t. 1.

RAMOS, Vitor de Paula. Onus da prova no processo civil: do ônus ao dever de provar. 2. ed. São Paulo: RT, 2018.

RÁO, Vicente. Ato jurídico. São Paulo: Max Limonad, 1961.

RODRIGUES JR., Otavio Luiz. Direito Civil Contemporâneo: estatuto epistemológico, Constituição e direitos fundamentais. 2. ed. Rio de Janeiro: Forense Universitária, 2019.

SCOZZAFAVA, Oberdan, Tommaso. Enciclopedia del Diritto. Onere (nozione). Milão: Giuffrè, 1980, XXX, p.99-113.

SICA, Heitor Vitor Mendonça. Preclusão. 2. ed. São Paulo: Atlas, 2008.

SILVA, Paula Costa e. Acto e Processo: regressando ao dogma da irrelevância da vontade na interpretação e nos vícios do acto postulativo. São Paulo: RT, 2019. 

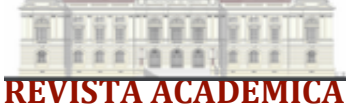

Faculdade de Direito do Recife

Vol.92 N.02 - Anno CXXIX

STEFANO, Giuseppe de. Enciclopedia del Diritto. Onere (dir. proc. civ). Milão: Giuffrè, 1980.p. 113-126.

TALAMINI, Eduardo; WAMBIER, Luiz Rodrigues. Curso Avançado de Processo Civil. 17. ed. São Paulo: RT, 2018.

TARELLO, Giovanni. Materiali per uma storia della cultura giuridica. Bologna: Il Mulino, 1974. v. 4.

TARUFFO, Michele. O ônus como figura processual. Revista Eletrônica de Direito Processual, Rio de Janeiro,v. 11, p. 420-431, 2013.

TUCCI, José Rogério Cruz e. Francesco Carnelutti: vida e obra. Contribuição para o estudo do processo civil. São Paulo: Migalhas, 2017.

VARELA, João de Matos Antunes. Das obrigações em geral. 10. ed. Coimbra: Almedina, 2000. V. 1 .

VILANOVA, Lourival. Causalidade e Relação no Direito. 4.ed. São Paulo: RT, 2000.

WOLKART, Erik Navarro. Análise Econômica do Processo Civil. São Paulo: RT, 2019. 